\title{
Conversion of phosphogypsum to potassium sulfate and calcium carbonate in aqueous solution
}

\author{
Y. Ennaciri, F.E. Mouahid, A. Bendriss and M. Bettach \\ Laboratoire de Physico-Chimie des Matériaux, Faculté des Sciences, El Jadida
}

\begin{abstract}
The dissociation of the phosphogysum by the liquid route which is the object of our work, is most appropriate and little expensive. Indeed, it leads to materials of direct application. The present work has for objective to study the decomposition of the phosphogypsum by the soft chemistry into valuable products such as $\mathrm{K}_{2} \mathrm{SO}_{4}$ and $\mathrm{CaCO}_{3} . \mathrm{K}_{2} \mathrm{SO}_{4}$ is a fertilizer which is highly recommended in the field of the agriculture, while $\mathrm{CaCO}_{3}$ can be used in the fields of the industry (cement) and the environment. According to the obtained results, we notice that the decomposition of the phosphogypsum in aqueous solution is very workable, reproducible, inexpensive and it is an ecologically interesting reaction. This reaction is made at room temperature and in aqueous environment, by giving two valuable products $\mathrm{K}_{2} \mathrm{SO}_{4}$ and $\mathrm{CaCO}_{3}$. The reaction is total after one hour and a half.
\end{abstract}

\section{INTRODUCTION}

In Morocco, the industry of phosphates is very important for the economic and social side of the country. This industry has to develop and innovate to meet the increasing demand in the field of the agriculture. This increasing development leads to an increasingly important production of phosphate fertilizers. It engenders the increase of the quantity of the phosphogypsum. In front of this important quantity and the problem of its storage or its elimination at the ecological level, numerous researchers and industrialists were interested in the study and the valorization of this product as a material of embankment work (pavement covering, roads,...) [1], of construction (cement, plaster) [2-5] or as fertilizing in the field of the agriculture.[6] Research and industrialist works are realized to produce the sulphuric acid from the recuperated sulfur. But the high cost of the reaction of thermal decomposition of the phosphogypsum and the abundance of the sulfur makes these attempts useless.

The decomposition of the phosphogypsum by liquid route is very interesting because it is less expensive and allows having marketable products which finds their applications in several industrial domains. The research and works on the transformation of the phosphogypsum into products valued by this way remain rare and insufficient. Among these, we can quote:

\section{Synthesis of ammonium sulphate}

According to Sacher, the manufacturing of the sulfate of ammonium $\left(\mathrm{NH}_{4}\right)_{2} \mathrm{SO}_{4}$ is known since the $\mathrm{XIX}^{t h}$ century. The reaction is made by paddling of carbon dioxide in a solution containing the phosphogypsum and the ammonia water [7]. We can schematize this chemical reaction by the following reaction equation:

$$
\begin{aligned}
& \mathrm{CaSO}_{4}, 2 \mathrm{H}_{2} \mathrm{O}+\left(\mathrm{NH}_{4}\right)_{2} \mathrm{CO}_{3} \rightarrow\left(\mathrm{NH}_{4}\right)_{2} \mathrm{SO}_{4} \\
& +\mathrm{CaCO}_{3}+2 \mathrm{H}_{2} \mathrm{O} .
\end{aligned}
$$

\section{Synthesis of potassium sulfate}

For its utility in the cultures of high quality, the potassium sulphate is a very important potash. It is especially used for the cultures sensitive to the chlorine to replace the fertilizer $\mathrm{KCl} . \mathrm{K}_{2} \mathrm{SO}_{4}$ is obtained by the attack of $\mathrm{KCl}$ with the sulphuric acid. Some researchers tried to synthesize $\mathrm{K}_{2} \mathrm{SO}_{4}$ from the phosphogypsum and another ore such as the sylvinite or $\mathrm{KCl}$. The gypsum and the sylvinite are abundant ores. They can be used for the synthesis of $\mathrm{K}_{2} \mathrm{SO}_{4}$ in aqueous environment. We obtain the glaserite which reacts with the sylvinite in order to give $\mathrm{K}_{2} \mathrm{SO}_{4}$ [8].

a) $4 \mathrm{CaSO}_{4}, 2 \mathrm{H}_{2} \mathrm{O}+6 \mathrm{KCl}, \mathrm{xNaCl} \rightarrow 3 \mathrm{~K}_{2} \mathrm{SO}_{4}, \mathrm{Na}_{2} \mathrm{SO}_{4}$ $+4 \mathrm{CaCl}_{2}+(x-2) \mathrm{NaCl}+8 \mathrm{H}_{2} \mathrm{O}$

b) $3 \mathrm{~K}_{2} \mathrm{SO}_{4}, \quad \mathrm{Na}_{2} \mathrm{SO}_{4}+2 \mathrm{KCl}, \quad x \mathrm{NaCl} \rightarrow 4 \mathrm{~K}_{2} \mathrm{SO}_{4}+$ $4 \mathrm{CaCl}_{2}+(\mathrm{x}+2) \mathrm{NaCl}+8 \mathrm{H}_{2} \mathrm{O}$.

It is also possible to produce potassium sulfate by double decomposition of potassium chloride and phosphogypsum in aqueous ammonia solution at room temperature. The reaction is proposed by Fernandez and al [9]:

$$
\mathrm{CaSO}_{4}, 2 \mathrm{H}_{2} \mathrm{O}+2 \mathrm{KCl} \rightarrow \mathrm{K}_{2} \mathrm{SO}_{4}+\mathrm{CaCl}_{2}+2 \mathrm{H}_{2} \mathrm{O} \text {. }
$$

In 1999, Abu-Eishah and al [10], prepared $\mathrm{K}_{2} \mathrm{SO}_{4}$ from the phosphogypsum and $\mathrm{KCl}$ with the presence of $\mathrm{HCl}$, isopropanol and ammonia. The presence of ammonia privilege the formation of $\mathrm{K}_{2} \mathrm{SO}_{4}$ and prevents the formation of complex salts such as the syngenite $\left(\mathrm{K}_{2} \mathrm{SO}_{4}, \mathrm{CaSO}_{4} \mathrm{H}_{2} \mathrm{O}\right)$ or / and the goergeyite $\left(\mathrm{K}_{2} \mathrm{SO}_{4}, 5 \mathrm{CaSO}_{4}, \mathrm{H}_{2} \mathrm{O}\right)$ [11].

\section{Decomposition of phosphogypsum by potassium carbonate in aqueous solution}

Based on the previous works relative to the decomposition of the phosphogypsum by liquid route, we combined the reaction of preparing $\mathrm{K}_{2} \mathrm{SO}_{4}$ from the phosphogypsum and $\mathrm{KCl}$ and the reaction of preparing $\left(\mathrm{NH}_{4}\right)_{2} \mathrm{SO}_{4}$ from the phosphogypsum, the carbon dioxide and the ammonia, 
which require more complicated experimental conditions, in the simple following reaction:

$$
\mathrm{K}_{2} \mathrm{CO}_{3}+\mathrm{CaSO}_{4}, 2 \mathrm{H}_{2} \mathrm{O} \rightarrow \mathrm{K}_{2} \mathrm{SO}_{4}+\mathrm{CaCO}_{3}+2 \mathrm{H}_{2} \mathrm{O} .
$$

The equilibrium is easily moved in the sense of formation of $\mathrm{K}_{2} \mathrm{SO}_{4}$ and $\mathrm{CaCO}_{3}$, because this last one is less soluble than the phosphogypsum.

In this work, we will use the Moroccan phosphogypsum as raw material to transform it into marketable products which are $\mathrm{K}_{2} \mathrm{SO}_{4}$ and $\mathrm{CaCO}_{3}$. We will study the profitability of this reaction, to look for these conditions optimum such as the initial concentrations and the time reaction.

\section{EXPERIMENTAL}

The phosphogypsum used during this work, comes from the waste of the preparation of phosphoric acid in the complex Maroc phosphore settled at Jorf Lasfar near El Jadida. It undergoes a lot of washes to eliminate the residual acidity, the salts and the suspension material which floats on the surface of the washing water (organic matter). The washed phosphogypsum presents an humidity rate of $20 \%$. The insoluble part (silica, ore not attacked, ...) determined by attack of the phosphogypsum with $\mathrm{HCl}$, is estimated at $0.6 \%$. Reactants mixtures are prepared from the washed phosphogypsum and potassium carbonate taken in stœchiometric quantities (mole with mole) which are put in volumes of water having well determined concentrations. These mixtures are put under stirring at room temperature during different times. At the end of the reaction, the mixture undergoes a vacuum filtration. The obtained solid product, which contains $\mathrm{CaCO}_{3}$, is dried in the oven at $100{ }^{\circ} \mathrm{C}$. The filtrates are put in the oven at $40^{\circ} \mathrm{C}$ to re-crystallize the salt $\mathrm{K}_{2} \mathrm{SO}_{4}$.

\section{RESULTS AND DISCUSSION}

\subsection{Monitoring of the reaction by measuring $\mathrm{pH}$}

To follow the conversion of the phosphogypsum to potassium sulphate, we thought to study the variation of the $\mathrm{pH}$ during the reactions by varying the time for different concentrations.

The obtained results are schematized on the figure 1 . We notice that the $\mathrm{pH}$ decreases then becomes constant for the concentrations 0.1 until $0.4 \mathrm{~mol} / \mathrm{l}$. For the concentrations 0.5 and $0.6 \mathrm{~mol} / \mathrm{l}$, the $\mathrm{pH}$ passes by a minimum then it increases and becomes constant. The stability of the $\mathrm{pH}$ after a while, informs us about the end of the reaction. The transition by a minimum for the concentrations 0.5 and $0.6 \mathrm{~mol} / \mathrm{l}$, is due to a saturation of the solution in $\mathrm{K}_{2} \mathrm{SO}_{4}$ which begins to crystallize and lead to an increase of the $\mathrm{pH}$ which stabilizes later. From the curves of the evolution of the $\mathrm{pH}$ for the various concentrations, we conclude that the $\mathrm{pH}$ becomes stable after a time of one hour and a half, it is the necessary time to transform completely the phosphogypsum into $\mathrm{K}_{2} \mathrm{SO}_{4}$.

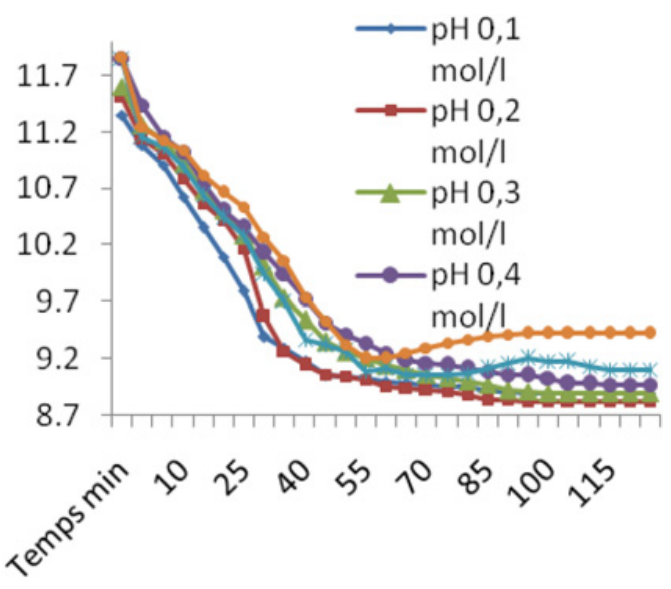

Figure 1. $\mathrm{pH}=\mathrm{f}(\mathrm{t})$ for different concentrations.

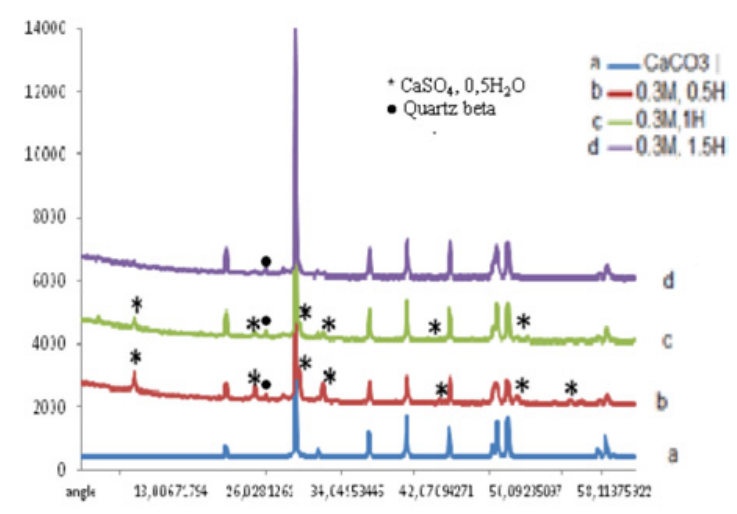

Figure 2. Diffractograms of the powders obtained for the concentration $0.3 \mathrm{~mol} / \mathrm{l}$ at different times.

\subsection{X-ray diffraction analysis}

In this paragraph, we present the results of the characterization by X-ray diffraction of obtained powders and salts. We limit these results to the concentrations $0.1 ; 0.3$ and 0.6 mole/l. The first one corresponds to a diluted concentration, the second is intermediate. The concentration $0.6 \mathrm{~mole} / \mathrm{l}$ corresponds to the limit of solubility of $\mathrm{K}_{2} \mathrm{SO}_{4}$ in the water. Once the solution becomes supersaturated, $\mathrm{K}_{2} \mathrm{SO}_{4}$ crystallizes. Thus, the separation of $\mathrm{CaCO}_{3}$ and $\mathrm{K}_{2} \mathrm{SO}_{4}$ will not be total. The choice of a concentration raised without reaching the saturation, allows us to spare the quantity of used water. We concluded that for duration lower or equal than one hour, the decomposition of the phosphogypsum is not total for the various concentrations, there is always a presence of $\mathrm{CaCO}_{3}$ and $\mathrm{CaSO}_{4}, 1 / 2 \mathrm{H}_{2} \mathrm{O}$. After one hour and a half, the unique phase present in the powder is $\mathrm{CaCO}_{3}$. For the filtrate, when the reaction is not total (time lower than one hour), there is $\mathrm{K}_{2} \mathrm{CO}_{3}$ which does not have reacted with the formed $\mathrm{K}_{2} \mathrm{SO}_{4}$.

Figures 2 and 3 represent the diffractograms XRD of powders and filtrates of the concentration $0.3 \mathrm{~mol} / \mathrm{l}$. The diffractograms of the concentrations 0.1 and $0.6 \mathrm{~mol} / \mathrm{l}$ are similar to those of $0.3 \mathrm{~mol} / \mathrm{l}$. The comparison of these curves with that of the pure state, shows well that the decomposition of the phosphogypsum is total from one hour and a half, even if we vary the concentration until 


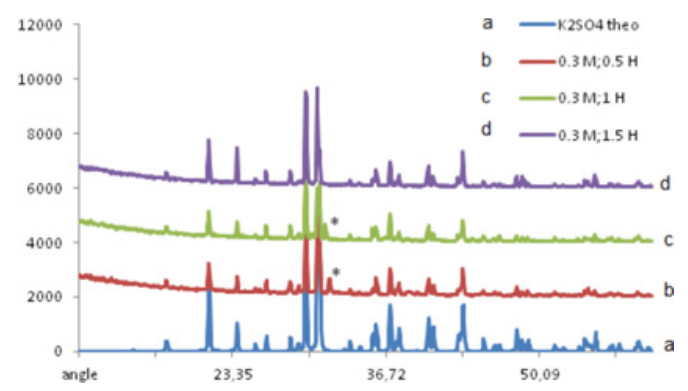

Figure 3. Diffractograms of the filtrates obtained for the concentration $0.3 \mathrm{~mol} / \mathrm{l}$ at different times.

Table 1. ICP analysis of phosphogypsum and calcium carbonate.

\begin{tabular}{|l|c|c|c|c|c|}
\hline & $\mathrm{Ba}$ & $\mathrm{Hg}$ & $\mathrm{Pb}$ & $\mathrm{Si}$ & $\mathrm{P}$ \\
\hline $\mathrm{CaCO}_{3}$ & 42.24 & 0.567 & 3.095 & 865.68 & 2071.19 \\
\hline phosphogypsum & 23.11 & 0.654 & 0.733 & 484.58 & 1276.03 \\
\hline
\end{tabular}

$0.6 \mathrm{~mol} / \mathrm{l}$. These results are in accordance with those obtained from the curves of the $\mathrm{pH}$ measurements.

\subsection{Chemical elements distribution}

We have done chemical analysis to know the distribution of the impurities contained in the phosphogypsum, and the carbonates of calcium $\mathrm{CaCO}_{3}$ during the transformation of this phosphogypsum. The following table shows the obtained results.

We notice that the distribution of these chemical elements is reasonable and respects the molar ratio between the phosphogypsum and the calcium carbonate $\left(\mathrm{M}\left(\mathrm{CaSO}_{4}, 2 \mathrm{H}_{2} \mathrm{O}\right) / \mathrm{M}\left(\mathrm{CaCO}_{3}\right)=1.78\right)$. That is why the contents of those elements are almost doubled when we pass from the phosphogypsum to $\mathrm{CaCO}_{3}$. The silica, the barium and the phosphor result from the non-attacked matter. Their contents are comparable to those met in the literature.The content in mercury and lead in the phosphogypsum and in the calcium carbonate is anyway lower than the tolerated limit.

\section{CONCLUSION}

We conclude from this study that the reaction is reproducible. The best efficiency for the decomposition of the phosphogypsum, in two pure products $\mathrm{CaCO}_{3}$ and $\mathrm{K}_{2} \mathrm{SO}_{4}$, is obtained by taking into account the following parameters:

- The temperature is the ambient.

- The reaction is made mole per mole between the phosphogypsum and the carbonate of potassium.

- The phosphogypsum is wet.

- The optimal limit concentration is $0.6 \mathrm{~mol} / \mathrm{l}$.

- The time of the reaction is- 1 hour and $30 \mathrm{~min}$.

\section{References}

[1] W. R. Anderson, gypsum aggregate, a viable commercial venture, Proceedings of the Second International Symposium on phosphogypsum, January 1988, publication FIPR n ${ }^{\circ}$ 01-037-055, p. 329 - 352.

[2] NEVEU B: valorisation des phosphogypses : procédé Charbonnages de France Chimie - Air Industrie, Congrès Technique de l'IFA, 13 - 16 septembre 1976.

[3] K. Murakami: utilization of chemical gypsum for Portland cement, Proceedings of the Fifth International Symposium on Chemistry of cement IV, Cement Association of Japan, 459 Tokyo 1969.

[4] M. Singh, M. Garg, and S.S. Rehsi. Purifying phosphogypsum for cement manufacture. Construction and Building Materials, 7(1), 939-951, 1992.

[5] P.K. Mehta and J.R. Brady. Utilization of phosphogypsum in Portland cement industry. Cement and Concrete Research, 7 :537-544, 1977.

[6] J. V Baird. and E. J. Kamprath (1980) : agricultural use of phosphogypsum on North Carolina Crops, Proceedings of the First International Symposium on phosphogypsum, publication FIPR $\mathrm{n}^{\circ}$ 01-001-017, p. $133-150$.

[7] Sacher, E. (1968). Ammonium sulfate from phosphogypsum. Proc. from the 1SMA Technical Conference, Brussels, 10-13 September 1968. ISMA68-654, 1-13.

[8] J. A. Fernandez-Lozano, A. Wint, Chem. Eng. J.,67, (1997), 1-7.

[9] J. A. Fernandez-Lozano, A. Wint, Chem. Eng. J., 23, (1982), 53-61.

[10] Samir I. Abu-Eishah, Ali A. Bani-Kananeh, Mamdouh A. Allawzi, Chemical Engineering Journal 76 (2000) 197-207.

[11] J.A. Fernandez Lozano, A. Wint, Production of potassium sulfate by an ammoniation process, Chem. Engineer (1979) 688. 